\title{
Broadcasting and Its Receiving Agent Based M-Commerce Model: Recognize M-commerce's Characteristics
}

\author{
Trivedi Jaydipkumar $\mathrm{H}^{1}$, Patel Paresh $\mathrm{N}^{2}$, Patel Hemant $\mathrm{N}^{3}$, Soni Jigar $\mathrm{D}^{4}$ \\ Assistant Prof. MCMSR College Visnagar.Indial Assistant Prof. MCMSR College Visnagar.India ${ }^{2}$ \\ Assistant Prof. MCMSR College Visnagar.India ${ }^{3}$ Assistant Prof. MCMSR College Visnagar.India ${ }^{4}$
}

\begin{abstract}
Broadcasting and Its receiving agent based M-commerce model functioning with the use of broadcasting and receiving agents in automatic and semiautomatic ways. There are certain aspects of the present model. Broadcasting and Its receiving agent based M-commerce model is influenced by these aspects. Driving factors, Architecture, Analysis of the Survey, Implementation of Algorithm, Equation and Variables, Transactions, Characteristics are considering as aspects of present model. There is observation for m-commerce characteristics. The work is trying to compare and observe the m-commerce characteristics from Broadcasting and its receiving agent based M-commerce model. At the end the work proves united working of Broadcasting and Its receiving agent based $\mathrm{M}$-commerce model and observe M-commerce characteristics.
\end{abstract}

Keywords: - M-Commerce, Broadcasting,

\section{INTRODUCTION}

Broadcasting and Its receiving agent based M-commerce business model recognized and observed in the market. The study is displaying "Broadcasting and Its receiving agent based M-commerce business model" as $\mathrm{m}$-commerce model. The work has intention of recognizing characteristics in the transaction of present $\mathrm{m}$ commerce model. The existing characteristics M-commerce like (1) Ubiquity, (2) Convenience, (3) Accessibility, (4) Personalization, (5) Localization have depicted. The work have objective of indicating Mcommerce model and characteristics with its supported proof of related research and data.

\section{LITERATURE REVIEW}

D Xiaojun,I Junchi, H Sho, have depicted unique features of mobile commerce in their work. In their work (1) Ubiquity, (2) Convenience, (3) Accessibility, (4) Personalization, Localization have instructed unique features of mobile commerce. ${ }^{[6]}$ Broadcasting and Its receiving agent based M-commerce business model have depicted by Trivedi J H, Pandya J G, Trivedi P H, Jani A N, In their work architectural development and transactions of broadcasting and its receiver based $\mathrm{m}$-commerce model have recognized. ${ }^{[2]}$ Rapid growth of customer use and adoption of the broadcasting agent and receivers: A Driving Factor is work developed by Trivedi J H, Pandya J G, Trivedi P H, Patel J B. The work observed existing m-commerce driving factors. The work also have introduced an advance driving factors.

\section{OBJECTIVES}

- Give the introduction of broadcasting and its receiving agent based m-commerce model as m-commerce model.

- Observe the $\mathrm{m}$-commerce characteristics in the broadcasting and its receiving agent based m-commerce model as m- Commerce model.

\section{RESEARCH METHODOLOGY}

Research investigation report have used for observing the transaction. Transaction have done by user or customer and filled the research investigation report for instructing the transaction. Secondary data have also been taken through questionnaire filled by customer or user.

\section{HYPOTHESIS}

- Broadcasting and Its receiving agent based M-commerce Business model have their transactions and recognizing $\mathrm{m}$-commerce characteristic from the transactions.

-The (1) Ubiquity, (2) Convenience, (3) Accessibility, (4) Personalization, (5) Localization are considering as M-commerce characteristics. 


\section{BROADCASTING AND ITS RECEIVING AGENT BASED M-COMMERCE BUSINESS MODEL}

The work is recognizance of Broadcasting and its receiving agent based M-commerce business model. It is based on Broadcasting and Its receiving agents. The architecture instructing broadcasting and its receiving agent significantly. ${ }^{[2]}$ See Figure 1 is the architecture of the present model. The customer is obtaining information from broadcasting receiving agent. Broadcasting agents and its receiving agents are based on (1) Radio Broadcasting, (2) Telephone Broadcasting, (3) Television Broadcasting, (4) Cable Radio Broadcasting (5) Satellite Broadcasting. (6) Web casting. There is Broadcasting based network or 3G network. Customer is establishing business transaction in two different automatic and semiautomatic ways. The semiautomatic way has sending order block. Customer is sending order by mob call, by mob messages, by e-mail through mob, by e-com, m-com sites at the order sending block. There is Broadcasting based network or 3G network between sender and receiver. Data authentication performs at this side. There is $3 \mathrm{G}$ mob, computer with internet, $3 \mathrm{G}$ TV, Data receiver, or Data base server are at order receiving agents block. Send data, send advertise, send service as goods as broadcasting. Send goods directly or made communication perform at business firm block. Send goods for broadcasting way or send to customer directly. The automatic way of sending order block indicate sending message or ordering through mobile or using NFC, or provide sensor information in the form of digital or analog form or Image. There is Broadcasting based network, 3G network or Sensor based network between sender and receiver. Embedded system is recognizing as receiver. Embedded system working collectively for order receiver using mobile sensor node or NFC receiving agent or digital data sensor or analog data sensor. There is data authentication and credit conformation. Provide goods automatically at business firm what it receive either from sensor node or collectively receives through mobile nodes. The automatic ways of sending goods to broadcasting agents directly for broadcasting purpose as goods or send goods directly through customer. Through any way transaction perform automatically but sending order agent, network and embedded system as receiver always remain for completing transactions. There are below explained aspects like (1) Driving factors, (2) Architecture, (3) Analysis of The Survey, (4) Implementation of algorithm, (5) Equation And Variables, (6) Transactions. (7) Characteristics.

(1) Driving Factors: For establishing m-commerce the driving factors play important role. The work has highlighted existing driving factors and advance driving factors.

Existing driving factors: Modernization of technology, a consideration of new value chain and demand for customer, exponential growth of customer interest and adoption of the internet and ecommerce, Development of real-time transfer of data over $2.5 \mathrm{G}$ and $3 \mathrm{G}$ network will enhance faster data transmit ion are considering as driving factor for m-commerce.

Advance driving factors: Rapid growth of customer use and adoption of the broadcasting agent and receivers is considered as an advance driving factors. ${ }^{[1]}$ Present model is highly influenced by this driving factor. "Rapid growth of customer use and adoption of the broadcasting agent and receivers: A Driving Factor" the research work have proved the advance driving factor. ${ }^{[1]}$

\section{(2) Architecture:}

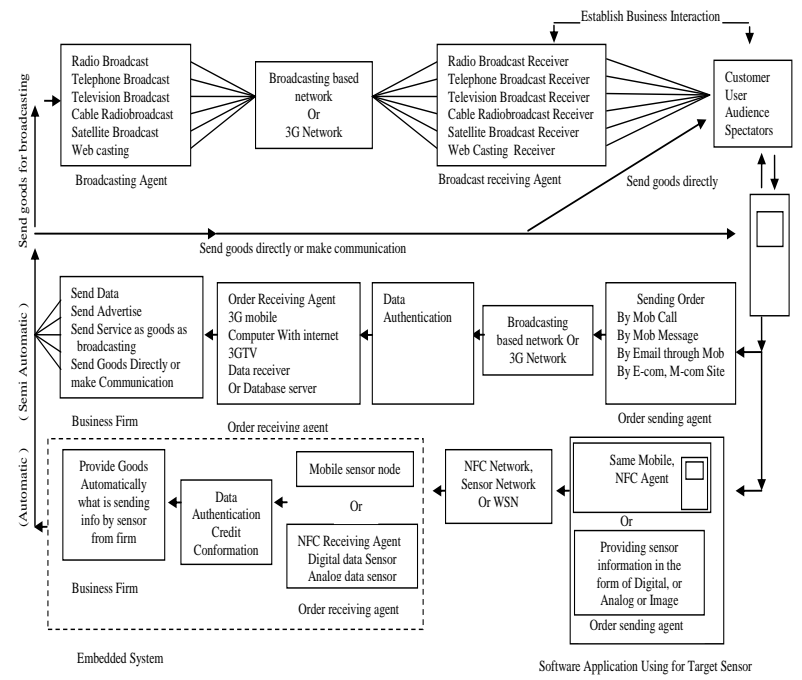

Figure 1: Architecture of the Broadcasting and its receiving agent based M-commerce business model. 
(3) Analysis Of The Survey: M-commerce based business transactions have performed at the real market place. The market survey has been performed for proving the functionality of the broadcasting and its receiving agent based M-commerce business model. ${ }^{[3]}$ Questionnaire have been using as research tool or methodology. The surveys have used 90 questionnaires and (19) question at first section and (11) questions at the second sections. The technocrats of North Gujarat, India have filled the data and prove their m-commerce based transactions. Broadcasting and its receiving agent based transactions have performed through (6) broadcasting agents and their (6) receivers. Observation Result have obtained in the research work done on "Broadcasting And Its Receiving Agent Based M-Commerce Business Model Functioning In The Market" ${ }^{[3]}$

Two question of $(90+90)=180$ question.

\begin{tabular}{|l|l|l|l|}
\hline $\begin{array}{l}\text { Tr. } \\
\text { No }\end{array}$ & $\begin{array}{l}\text { Transaction Based } \\
\text { On Broadcasting Agents }\end{array}$ & Broadcasting Receiving Agent & $\begin{array}{l}\text { Observed } \\
\text { Questions }\end{array}$ \\
\hline 1 & Radio Broadcasting & Radio As Receiver & $7 / 180$ \\
\hline 2 & Television Broadcasting & Television As Receiver & $31 / 180$ \\
\hline 3 & Web Casting & $\begin{array}{l}\text { Computer System, Mobile With } \\
\text { Internet }\end{array}$ & $36 / 180$ \\
\hline 4 & Satellite Broadcasting & Satellite Broadcasting Receiver & $37 / 180$ \\
\hline 5 & Telephone Broadcasting & Mobile Phone As Receiver & $35 / 180$ \\
\hline 6 & Cable Radio Broadcasting & Cable Radio As Receiver & $6 / 180$ \\
\hline
\end{tabular}

Table 1: Broadcasting and Its Receiving Agents

(4) Implementation of Algorithm:

"Broadcasting And Its Receiving Agent Based M-Commerce Model" has been implicating in authentic ways for customer as well as system level. M-Commerce background using authentic algorithm for customer authorization. Designing and prototyping encryption algorithm have performed for the purpose of present model based transaction. ${ }^{[8]}$ The study is indicating user name of e-mail address as encryption key.

\section{Step 1: TRIVEDI-PRATIKSHA-J}

(Plain text as message obtained, converts the character to its related alphabetical digit like $A=01, B=02, C=03$, $\mathrm{D}=04$.In the plain text blanks seems as "-“." Indicates Space as 00)

Step 2: 20180922050409001618012009111908010010

(Decide the digital block of the string as per the length of user name of e-mail address's digit)

Step 3: Pbpathak1978(Got from mrjlecturer@yahoo.com.

The encryption key formed on the basis of user name of e-mail address taken form e-mail message for business Transaction is taking user name of e-mail address only without "@”" and rest of the address like yahoo mail.com)

16021601090801111978 (Encryption key got from username, Converts the character to its related alphabetical Digit like $\mathrm{A}=01, \mathrm{~B}=02, \mathrm{C}=03, \mathrm{D}=04 \ldots$. )

Step 4: 20180922050409001618012009111908010010

$\underline{16021601090801111978 \quad 160216010908011119}$

$36202523141210113596 \frac{172225122816021129}{10}$

(Sum the digital block of the string with Encryption key)

\section{Step 5: CFB0BEBCADABA0AACEIF AGBBBEABBHAF0BAABI}

( The obtained result of the sum from step 4 converted digital string into alphabetical String like $3=C$, $9=I$, and keep Zero 0 remain Same for further task, It means 0 is encrypted as 0 .

\section{Encrypted Message:}

CFB0BEBCADABA0AACEIF AGBBBEABBHAF0BAABI

Step 6: CFBOBEBCADABA0AACEIF AGBBBEABBHAFOBAABI

36202523141210113596172225122816021129

( Converted the alphabetical string into digital String like C=3, I=9, and keep Zero "0" remain Same for further task, It means " 0 " is encrypted as " 0 " only.)

Step 7: 36202523141210113596172225122816021129

$\underline{16021601090801111978} \underline{160216010908011119}$

$2 0 1 8 0 9 2 2 0 5 0 4 0 9 0 0 1 6 1 8 \longdiv { 0 1 2 0 0 9 1 1 1 9 0 8 0 1 0 0 1 0 }$

(Subtracted the digital block of string with Encryption key)

Step 8: 20180922050409001618012009111908010010

T R I VE D I - PR A T IK S HA - J

(Alphabetical string on the basis of result acquired from subtraction) 
(5) Equation And Variables Constructs The M-Commerce Model:

The work has observed broadcasting and Its receiving agent based model related equations. ${ }^{[4]}$

1. Driving Factor can be decided on the basis of equation. ${ }^{[4]}$

Equation can decide driving factor of $\mathrm{m}$-commerce model.

$$
\sum_{i=1}^{n} \operatorname{Tr} . \mathrm{V}_{(\mathrm{i})} \rightarrow \mathrm{MDF}
$$

Explanation 1:- M-commerce Driving Factors (MDF) is based on transaction variable. Here m-commerce transaction variables will be decided from the transaction. Transaction is divided in to variable.

$$
\operatorname{Tr} . \mathrm{V}(1)+\operatorname{Tr} . \mathrm{V}(2)+\operatorname{Tr} . \mathrm{V}(\mathrm{n}) \rightarrow \mathrm{MDF}
$$

The business transaction variable is important for deciding M-commerce Driving Factors.

2. M-Commerce Model (MM) based on M-commerce Driving Factors (MDF) and M-commerce Driving Factors (MDF) is based on transaction variables.

M-commerce Model can decide on the basis of Equation. ${ }^{[4]}$

$$
\sum_{i=1}^{n} \operatorname{Tr} . \mathrm{V}_{(\mathrm{i})} \rightarrow \mathrm{MDF} \rightarrow \mathrm{MM}
$$

Explanation 2:- The equation stats that MM, M-commerce model is depend On MDF, M-commerce driving factors. As stated before M-commerce Driving Factors (MDF) is based on transaction variable. Transaction is divided in to variable. $\operatorname{Tr} . \mathrm{V}(1)+\operatorname{Tr} . \mathrm{V}(2)+\ldots \operatorname{Tr} . \mathrm{V}(\mathrm{n}) \rightarrow \mathrm{MDF}$

Case Transaction have performed and proved the Equation. ${ }^{[4]}$

3. Dependency of M-commerce model on the basis of MDFcan be decided by below mention Equation. ${ }^{[4]}$

$$
\mathrm{MDF} \rightarrow \mathrm{MM}
$$

Explanation 3:- The equation proves that M-commerce model also individually depend on m-commerce driving factor. There are different kind driving factors and there related $\mathrm{m}$-commerce model have depicted and that proves the dependencies with m-commerce driving factor. ${ }^{[4]}$

\begin{tabular}{|l|l|l|}
\hline No & MDF & MM \\
\hline 1 & Value Chain Evolution & User Fee Business Model \\
\hline 2 & Active Customer Demand & NTT-DOCOMO \\
\hline 3 & $\begin{array}{l}\text { Rapid growth of customer use and adoption } \\
\text { of the broadcasting agent and receiver }\end{array}$ & $\begin{array}{l}\text { Broadcasting and Its receiving } \\
\text { agent based m-commerce model }\end{array}$ \\
\hline
\end{tabular}

Table 2: M-commerce model and driving factors

4. Dependency of M-commerce model on the basis of transaction variables can be displayed below mention Equation. ${ }^{[4]}$

$$
\sum_{i=1}^{n} \operatorname{Tr} . \mathrm{V}_{(\mathrm{i})} \rightarrow \mathrm{MM}
$$

Explanation 4:-M-commerce model is independently depend on transaction variables. ${ }^{[4]}$

(6) Transactions: There is business transactions based on broadcasting and its receiving based m-commerce business model performed in semi automatic and automatic ways. The RIR has proved the transactions. ${ }^{[5]}$

(I) Automatic Transaction

\section{Transaction 1:}

T.V Broadcasting based transaction performed, purchasing an item that broadcasted on T.V at shopping mall.

1. Purchasing the item using T.V Broadcasting:

Cell Phone utilization bill payment has been recharged through Airtel Money using Cell Phone, at the same time advertisement for the recharge the phone and discount was broadcasting at shopping mall at Ahmedabad, India. And purchase occurs.

2. Tools Utilization: T.V sets at shopping mall, Digital Display for displaying the item and Cell Phone. 
3. Tools Utilization for Broadcasting: T.V. that is hanged at shopping mall, it has T.V/Dish sets, T.V Channel sets. Advertise displayed on it either in video or audio form.

4. Source of Data: RIR displayed fact about the transaction done at a place practically.

5. Combination of Data Utilized By System:

- Electric Power of capacity of $1000 \mathrm{uf} / 25 \mathrm{~V}$

- Digital data as 0 and 1 in bit format.

- Waves used by Cell Phone with high frequency radio waves.

6. Hardware Utilized:

- LCD of $16 * 12$ capacities.

- Microcontroller, 8051 and AT89x

- Barcode Reader Modem

-Transformer of $12 \mathrm{~V}$ capacity.

- Filter of 1000uf/25V

-Voltage Regulator of 7805/7812

-Mobile Phone Software System used is Android

-Computer System with .Net Framework with C\#

7. Utilized Services:

- Internet services with BSNL broadband services.

- Banking services with internet facilities and credit card/debit Card performing authentication, credit conformation

8. RIR Provided Fact: RIR displayed the fact on the basis of transaction done at a place practically.

- Obtained hard and soft copy of transaction bill that is done

Using Airtel Money

- Photo of the display screen and transaction.

- Transaction Detail.

9. Place Where Transaction Performed: - Shopping Mall

\section{Transaction 2:}

1. Purchase the item using radio broadcasting or DTH direct to home services with radio broadcasting: Recharging the Airtel Dish T.V with Airtel Money using cell phone, advertise broadcasted on T.V based radio (DTH) at Visnagar, India. ${ }^{[5]}$

2. Tools Utilization: Radio Transmission Receiver on T.V Sets with DTH tool kit at home

3. Tools Utilization for Broadcasting:T.V Dish / T.V Channel tool kit. Cell Phone with availability of internet and Airtel Money, the commercial information advertised on in a voice or sound form.

4. Source of Data: RIR obtained information of the transaction.

5. Combination of Data Utilized By System:

- Electric Power of 1000uf/25 V

- Digital Data as 0 and 1 form as bit format.

- Waves used by cell phone is high frequency radio waves

- Analog Data in voice or sound format

6. Hardware Utilized:

-LCD of $16^{*} 12$

-Microcontroller with 8051 and AT89x

-DTH Setup Box as broadcast receiving tool and receive data from satellite

-Voltage Regulator 7805/7812

- Computer Software System, Software of radio waves transmission receiver on T.V, Cell Phone, Laptop, Computer, Teblet, Radio Receiver.

7. Utilized Services:

-Mobile Telephone Service (MTS) with cellular or VHP radio system which is related to PSTN public switched telephone network.

-Banking services with internet facilities and credit card /debit Card performing authentication and credit conformation.

-Mobile phone Service like (i) General Telephony Services (ii) Airtel Money Services

8. RIR Provided Fact: RIR displayed the fact on the basis of transaction done at a place practically.

-Transaction payment bill that performs using Airtel Money

-Photo of the display screen and transaction.

-Transaction Detail

-Audio Video File

9. Place Where Transaction Performed: Home 


\section{Transaction 3:}

1. Purchase the item using web casting: Purchase a pen drive that is advertised on a websites as web casting, receive information at all IP

2. Tools Utilization: Internet competent mobile phone working as computer node.

3. Tools Utilization for Broadcasting:

Mobile phone with internet display, commercial information displayed and obtained as website based display at all the phone as computer node

4. Source of Data: Fact to be obtained by RIR based on transaction.

5. Combination of Data Utilized By System:

- Electric Power of 1000uf/25 V

- Digital Data as 0 and 1 form as bit format.

- Waves used by cell phone is high frequency radio waves

- Analog Data in voice or sound format

6. Hardware Utilized:

-Telephone or Mobile Phone of Samsung Company

7. Utilized Services

-Mobile Telephone Service (MTS) with cellular or VHP radio system which is linked to PSTN network

-Banking Services with internet services

-Courier Service of BlueD

8. RIR Provided Fact: RIR displayed the fact on the basis of transaction done at a place practically.

-Transaction payment bill performs using Internet Banking

-Photo of the display screen and transaction.

-Transaction Detail

-Audio Video File

9. Place Where Transaction Performed:

-Computer Node as mobile phone

(II) Semi Automatic Transaction

Transaction 2:

1. Purchase the item displaying on speakers based broadcasting as local broadcasting at shopping mall and payment is transferring on that spot as transferring balance to the account of that shopping mall. The commercial information as advertise displaying on it.

2. Tools Utilization: Audio speakers settled at shopping mall.

3. Tools Utilization for Broadcasting:

An audio system is broadcasting the information through Mike, Audio Recording Displayer like computer system, External DVD/CD player, External Tap Recorder.

4. Source of Data: RIR displayed the fact on the basis of transaction done at a place practically.

5. Combination of Data Utilized By System:

- Electric power of $1000 \mathrm{uf} / 25 \mathrm{~V}$

- Digital Data as 0 and 1 as bit.

-Analog data

6. Hardware and Software Utilized:

-LCD of $16 * 12$

-Microcontroller with 8051 and AT89x

-DTH Setup Box as broadcast receiving tool and or receive data from satellite

-Voltage Regulator 7805/7812

-Transformer of $12 \mathrm{~V}$

- Computer Software System, Printer, Barcode Reader as

advance barcode reader.

-Speakers System, Recorder System, T.V

7. Utilized Services

-Internet Service

-Banking Service

-Mobile Phone Services and Airtel Money service

8. RIR Provided Fact: RIR displayed the fact on the basis of transaction done at a place practically.

- Transaction Bill that is done using Airtel money.

- Photo of the display screen

- Transaction Detail and Audio File. 
9. Place Where Transaction Performed: Shopping Mall

(7) Characteristics: Broadcasting and Its receiving agent based m-commerce model has m-commerce characteristics. (1)Ubiquity, (2) Localization, (3) Accessibility, (4) Personalization or Simple Authentication, (5) Convenience

\section{M-COMMERCE EXISTING CHARACTRISTICS}

Unique features of mobile commerce have stated below mention features. ${ }^{[6]}$ (1)Ubiquity, (2)Convenience, (3) Accessibility, (4)Personalization, (5)Localization.

Features of m-commerce, a whitepaper indicated (1) Simple Authentication, (2) Instant Connectivity, (3) Localization (4) Immediacy (5) Ubiquity ${ }^{[7]}$

\section{OBSERVING M-COMMERCE'S CHARACTRISTICS IN THE TRANSECTIONS OF THE PRESENT MODEL}

The work has pointed out broadcasting and its receiving agent based $\mathrm{m}$-commerce model and also pointed out below mention m-commerce characteristics.

\section{(1) Ubiquity: (Real Time Access, Independent of Users location)}

It is the service that a person can avail of service and can do transaction largely independent of his current geographic of service. Broadcasting agents and Its receiving agents providing their services for the customer on the basis of (1) Radio Broadcasting, (2) Telephone Broadcasting, (3) Television Broadcasting, (4)Cable Radio Broadcasting (5) Satellite Broadcasting. (6) Web casting. The customer perform m-commerce transactions either automatic or semiautomatic ways of transactions. So it is real time access and observed Independent of users location of all transaction as per below.

Ubiquity has observed through questionnaires filled by the customer who were engaged in the transaction at the places of the Gujarat in India.

-There are 7 customers out of 180 customers have observed who used radio broadcasting service as $\mathrm{m}$ commerce transactions.

- There are 31 customers out of 180 customers have observed who used TV broadcasting service as mcommerce transactions.

-There are 37 customers out of 180 customers have observed who used satellite broadcasting service as mcommerce transactions.

-There are 35 customers out of 180 customers have observed who used telephone broadcasting service as mcommerce transactions.

-There are 6 customers out of 180 customers have observed who used cable radio broadcasting service as mcommerce transactions.

\section{(2) Localization: (Information and Services specific to the location)}

Location related services like T.V Broadcasting allow customer to offer goods and services. Purchasing the item using T.V Broadcasting: Cell Phone utilization bill payment has been recharged through Airtel Money using Cell Phone, at the same time advertisement for the recharge the phone and discount was broadcasting at shopping mall on T.V at Ahmedabad, India. And purchase occurs. So it is the instruction of the information and services specific to the location.

RIR (Research Investigation Report) provided the fact of the transactions. Purchasing the item using T.V Broadcasting, Tool Utilization, Combination of data utilized by the system, hardware utilization, utilized services, place where transaction performed.

\section{(3) Accessibility: (Available and alternative Contact)}

As indicated at architecture of the present model, the customer using automatic and semiautomatic ways for transactions. There is accessibility observed in the sending agents like (1) Order sending agents e.g cell phone, (2) Mobile and Mobile messages, (3)Computer with Internet and E-mail, (4) E-commerce sites, (5) Mcommerce sites and there is $3 \mathrm{G}$ based network, NFC based network which provide accessibility. ${ }^{[2]}$ The work shows available and alternate contact. Data sending on m-commerce site and the database table indicating accessibility in the screenshots indicated below. Example: 


\begin{tabular}{|c|c|c|c|c|}
\hline \multicolumn{3}{|c|}{ Table1: Quer...DATABASE.MDF) } & Default.aspx & \multirow{2}{*}{$\frac{\text { Defaul }}{\text { Credit }}$} \\
\hline & No & Name & Email & \\
\hline \multirow[t]{5}{*}{ 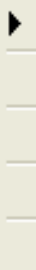 } & 42 & 2623381421 & BFBCCHADBA & 555 \\
\hline & 43 & 162125141217 & AFBABBEADABAG & 555 \\
\hline & 44 & 140827062820 & ADOHBGOFBHBO & 556 \\
\hline & 45 & $3826190934380 \ldots$ & CHBFAIOICDCH... & 557 \\
\hline & 46 & $1634141316260 \ldots$ & AFCDADACAFBF... & 558 \\
\hline
\end{tabular}

Figure 2: Instruction provided on site.

(4) Personalization or Simple Authentication: (Creating Services customized with an individual)

There is authentication services provided for customer only It is for the customers benefit and there is credit conformation services used for customer only. Broadcasting And Its Receiving Agent Based MCommerce Model has used authentication and credit conformation at automatic and semiautomatic ways of transaction. ${ }^{[8]}$ The work has instructed authentication algorithms. ${ }^{[8]}$ Encryption algorithm have used for storing data and also using for entering $\mathrm{m}$-commerce sites. Credit conformation can be observed and find comparison of the coupon number. The screen shot have displayed the database for the transactions.

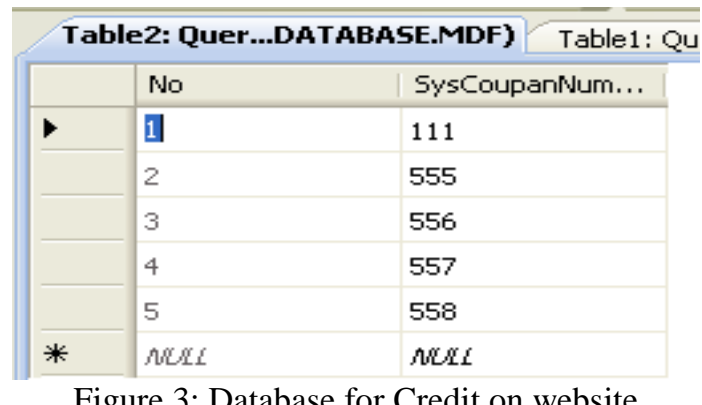

Figure 3: Database for Credit on website

\section{(5) Convenience: (Always at hand easy to use)}

M-commerce transactions have explored in two different ways as architecture has pointed out. Automatic and semi automatic way of transaction explored conveniently. ${ }^{[2]}$ All the transactions have done conveniently as per the broadcasting and receiving agent based m-commerce model. The m-commerce's sites are conveniently used by the customer for the transaction. Fig. 2 is the database which is the proof of the convenient transaction.

\section{DATA AND ANALYSIS}

Data for ubiquity as characteristics No (1):

A person can avail of service and can do transaction largely independent of his current geographic of service. It the real survey performed at market place and customer has used services as per below. ${ }^{[3]}$ Observed out of 180 Questions

\begin{tabular}{|l|l|l|l|}
\hline $\begin{array}{l}\text { Tr. } \\
\text { No }\end{array}$ & $\begin{array}{l}\text { Transaction Based On } \\
\text { Broadcasting Agents }\end{array}$ & Broadcasting Receiving Agent & $\begin{array}{l}\text { Observed } \\
\text { Questions }\end{array}$ \\
\hline 1 & Radio Broadcasting & Radio As Receiver & $7 / 180$ \\
\hline 2 & Television Broadcasting & Television As Receiver & $31 / 180$ \\
\hline 3 & Web Casting & Computer System, Mobile With Internet & $36 / 180$ \\
\hline 4 & Satellite Broadcasting & Satellite Broadcasting Receiver & $37 / 180$ \\
\hline 5 & Telephone Broadcasting & Mobile Phone As Receiver & $35 / 180$ \\
\hline 6 & Cable Radio Broadcasting & Cable Radio As Receiver & $6 / 180$ \\
\hline
\end{tabular}

Table 3: Broadcasting and Receiving Agents

Thus the study observed it is real time access and observed Independent of users location of all transaction

Data for localization as characteristics No (2): The transactional data is mentioning below.

1. Purchasing the item using T.V Broadcasting:

Cell Phone utilization bill payment has been recharged through Airtel Money using Cell Phone, at the same time advertisement for the recharge the phone and discount was broadcasting at shopping mall at Ahmedabad, India. And purchase occurs. 
2. Tools Utilization: T.V sets at shopping mall, Digital Display for displaying the item and Cell Phone.

3. Tools Utilization for Broadcasting: T.V. that is hanged at shopping mall, it has T.V/Dish sets, T.V Channel sets. Advertise displayed on it either in video or audio form.

4. Source of Data: RIR displayed fact about the transaction done at a place practically.

5. Combination of Data Utilized By System:

- Electric Power of capacity of $1000 \mathrm{uf} / 25 \mathrm{~V}$

- Digital data as 0 and 1 in bit format.

- Waves used by Cell Phone with high frequency radio waves.

6. Hardware Utilized:

- LCD of $16 * 12$ capacities.

- Microcontroller, 8051 and AT89x

- Barcode Reader Modem

-Transformer of $12 \mathrm{~V}$ capacity.

- Filter of $1000 \mathrm{uf} / 25 \mathrm{~V}$

-Voltage Regulator of 7805/7812

-Mobile Phone Software System used is Android

-Computer System with .Net Framework with C\#

7. Utilized Services:

- Internet services with BSNL broadband services.

- Banking services with internet facilities and credit card /debit Card performing authentication and credit conformation

8. RIR Provided Fact: RIR displayed the fact on the basis of transaction done at a place practically.

- Obtained hard and soft copy of transaction bill that is done Using Airtel Money

- Photo of the display screen and transaction.

- Transaction Detail.

9. Place Where Transaction Performed: Shopping Mall

Customer Utilized Broadcasting Agent and Its Receiver Name: T.V Broadcasting display and doing transaction at shopping moll at Ahmedabad In India.

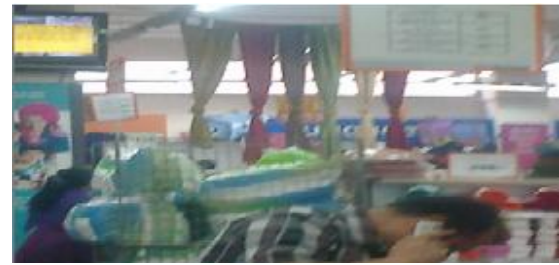

Figure 4: Shopping moll at Ahmedabad In India.

Thus the observation focused the instruction of the information and services specific to the location.

Data for personalization or simple authentication as characteristics No (3):

Primary Data:

1. Plain Text: TRIVEDI-PRATIKSHA-J

2. Encryption Key: Pbpathak1978

3. Encrypted Message obtained:

CFB0BEBCADABA0AACEIF AGBBBEABBHAF0BAABI

4. Ultimate Result: TRIVEDI-PRATIKSHA-J

\section{Secondary Data:}

Data to be used for algorithms and simulator in two cycles. ${ }^{[8]}$

\section{At First Cycle:}

1. Plain Text: TRIVEDI-JAYDIPKUMAR-H

2. Encryption Key: mrjlecturer

3. Encrypted Message obtained: CCCFAICDA00GBIBABH0FDC AGBGBFBCBFAFBACIAHAC

4. Ultimate Result: TRIVEDI-JAYDIPKUMAR-H

5. User name and other information indicated from received e-mail at system level:

Delivered-To: profjaydip@gmail.com

Received: by 10.64.229.75 with SMTP id so11csp94386iec;

Mon, 22 Jul 2013 21:44:06 -0700 (PDT)

X-Received: by 10.49.13.229 with SMTP id k5mr36234047qec.64.1374554645798; 
Mon, 22 Jul 201321:44:05 -0700 (PDT)

Return-Path:<mrjlecturer@yahoo.com>

At Second Cycle:

1. Plain Text: DARJI-JITENDRAKUMAR

2. Encryption Key: mcajayesh

3. Encrypted Message obtained: AG0DAIB0A0BEAEBHBH AHAG0EBH0BCFBFCB0ICA

4. Ultimate Result: DARJI-JITENDRAKUMAR

5. User name and other information indicated from received e-mail at system level:

Delivered-To: profjaydip@gmail.com

Received: by 10.64.229.75 with SMTP id

so11csp264956iec;Thu, 1 Aug 2013 02:22:03 -0700 (PDT)X-Received: by 10.67.10.236 with SMTP id ed12mr2801616pad.153.1375348922903;

Thu, 01 Aug 2013 02:22:02 -0700 (PDT)

Return-Path_mcajayesh@ahoo.co.in

Data for Convenience as characteristics No (4):

Here one automatic transaction done conveniently that is observed and obtains its transactional data. ${ }^{[5]}$ Number of transactions perform conveniently, out of all convenient transactions the work pointed out one convenient transaction.

Transaction: Automatic Transaction

Item To Be Purchased: There is pen drive purchase that is advertised on a websites as web casting (receive broadcasting and paying by using internet banking on mobile phone.

Customer Utilized Web casting Agent and Its Receiver Name: Computer Node, Mobile as Computer Node Data to be obtained for the transaction: Resulting message.

Research Inspection Report: Customer him self has filled data of the transaction done at moll.

Data for Accessibility as characteristics No (5): Figure no 2 is the instruction of database for m-commerce sites and data used with it is observed. The work shows available and alternate contact.

\section{RESULT AND TEST THE HYPOTHESIS}

(1) Ubiquity: A M-commerce characteristic

A person can avail of service and can do transaction largely independent of his current geographic of service. There are six transactions based on broadcasting agents and there are six broadcasting receiving agents who performed services which are regarded as Ubiquity: A M-commerce characteristic.

On the basis of questionnaires result; total 153 persons (customer) can avail of service using all broadcasting services.

(2) Localization: A M-commerce characteristic

RIR displayed the fact on the basis of transaction done at a place practically. The transaction need to be pointed out to prove the characteristics that A Cell Phone utilization bill payment has been recharged through Airtel Money using Cell Phone, at the same time advertisement for the recharge the phone and discount was broadcasting at shopping mall at Ahmedabad, India.

The RIR display the data for localization Example find in the real transaction obtained.

Place : Shopping mall at ahmedabad. See Fig. No. 4

(3) Personalization or Simple Authentication: At the architectural level there is authentication and also performs algorithms for authentication purposes.

User or customer's purchased coupon no and System registered coupon number is utilized and compare. If both the values find same than the customer is allowing for transaction.

(4) Accessibility: Websites based m-commerce sites and mobile phone based is using. Screen shot is instructing the accessibility. If the user is authentic he or she immediately allow for transaction.

(5) Convenience: Here one automatic transaction done conveniently that is observed.

As per the hypothesis the work got (1) Ubiquity, (2) Localization, (3) Personalization or Simple Authentication,

(4) Convenience are the characteristics.

\section{CONCLUSION}

Thus the study indicated broadcasting and its receiving agent based $\mathrm{m}$-commerce business model. The work has proved (1) Ubiquity, (2) Localization, (3) Personalization or Simple Authentication, (4) Convenience as the characteristics of $\mathrm{m}$-commerce. 


\section{REFERENCES}

[1] Trivedi J H, Pandya J G, Trivedi P H, Patel J B, Rapid growth of customer use and adoption of the broadcasting agent and receivers: A Driving Factor, IOSRJEN, Vol. 1,Issue 1,pp.61-65(2011-12) ISSN: 2250-3021.

[2] Trivedi J H, Pandya J G, Trivedi P H, Jani A N Broadcasting and Its receiving agent based M- commerce business model, Presented as poster presentation in cross disciplinary international seminar held at H.N.G.University, Patan.India. And gone for Publishing in the University Journal (2011).

[3] Trivedi J H, Darji J H, Parikh P P, Trivedi P H. Broadcasting And Its Receiving Agent Based MCommerce Business Model Functioning In The Market, IOSRJEN, Vol.2,Issue 8,pp.25-33(2012) ISSN: 2250- 3021.

[4] Trivedi J H, Pandya J G, Patel J M, Mithapara A K, M- Commerce Driving Factor and Transaction Variables: Aspect That Constructs The M-commerce Model, IOSRJEN, Vol.2, Issue 2,pp.135-141(201112) ISSN: $2250-3021$.

[5] Trivedi J H, Trivedi P H, Thakkar S T, Makwana M, Automatic and Semi Automatic Transaction of Broadcasting and It's Receiving Agent Based M- commerce Business Mode, IOSRJEN,Vol.3,Issue 2,pp.42-53(2013) ISSN: 2250-3021.

[6] D Xiaojun,I Junchi, H Sho, Unique features of mobile Commerce,TITECH, Tokyo, 152-8552, Japan

[7] Binary Mantra System, Features of M-commerce, A White Paper, U.K

[8] Trivedi J H, Trivedi P H, Darji J H, Patel H D, Designing and prototyping encryption algorithms: Working as secure M-commerce transaction of broadcasting and its receiving agent based $\mathrm{m}$ commerce model, IOSRJEN,Vol.3,Issue 8, pp.25-33 (2013) ISSN: 2250- 3021 